\title{
CONVERSAÇÕES: MODELO CIBERNÉTICO DA CONSTITUIÇÃO DO CONHECIMENTO/REALIDADE
}

\author{
Nize Maria Campos Pellanda*
}

\begin{abstract}
RE SU M 0 : Este artigo trata da discussão da aplicação de uma metodologia baseada em princípios cibernéticos com um grupo de pesquisadoras em educação no processo de construção de conhecimento por meio da Dinâmica das Conversações. Conversação é um dos pressupostos básicos da teoria de Humberto Maturana sobre Biologia da Cognição, a qual constitui o núcleo do marco teórico deste trabalho.
\end{abstract}

Palavras-chave: Conversações. Princípios cibernéticos. A utopoiesis. Construção de conhecimento/ subjetividade.

\section{CONVERSATIONS: A CYBERNETIC MODEL OF THE CONSTITUTION OF KNOMLEGE/ REALITY}

A BSTRA CT: This paper discusses the application of a methodology based on cybernetic principles to a group of education researchers, in the process of knowledge construction through Conversational D ynamics. Conversation is one of the basic assumptions of Humberto Maturana's Theory on Biology of Cognition, which is the core theoretical framework of this study.

Key words: Conversations. Cybernetic principles. A utopoiesis. Knowledge/ subjectivity construction.

* D outora em Educação e professora do Programa de Pós-Graduação em Desenvolvimento Regional da Universidade de Santa Cruz do Sul (UnISc). E -mail: nizepe@ portoweb.com.br 


\section{Introdução}

$E$ ste artigo trata de uma dimensão de um projeto de pesquisa mais amplo intitulado A utopoiesis. O referido projeto destina-se a responder à questão sobre a gênese do processo de construção de conhecimento num paradigma que considera que a realidade é gerada num sistema fechado para informações externas e aberto para a troca de energia. Trata-se, portanto, de uma realidade complexa que apresenta situações de autonomia e de conectividade ao mesmo tempo. Nessas condições, não há validação externa ou falseabilidade possíveis, mas coerências internas e autovalidações, à maneira de um sistema cibernético que se autocorrige.

Não cabe aqui discorrer sobre a totalidade do projeto, mas farei algumas considerações gerais sobre este com o objetivo de contextualizar este artigo. 0 que será destacado aqui é apenas um dos eixos metodológicos: - a Dinâmica das Conversações - que, à maneira de um fractal, contém a essência da metodologia da pesquisa como um todo. Baseados no pressuposto de Maturana de que a realidade se constitui nas conversações, usamos essa dinâmica para irmos construindo nosso processo de investigação. Diz ele: "Tudo o que nós, os seres humanos, fazemos como tal, o fazemos nas conversações. E aquilo que não fazemos nas conversações, de fato, não 0 fazemos como seres humanos" (Maturana, 1999, p. 47).

0 que estamos nos propondo, portanto, é refletir sobre o processo das conversações no grupo, em termos de como constituímos conhecimento e a nós mesmos numa perspectiva autopoiética. Nesse processo, a inclusão do observador na prática da investigação, por meio das conversações, responde à necessidade de um paradigma que não separa as diferentes dimensões da realidade.

\section{Por que a ênfase nas conversações?}

(...) o humano surge, na história evolutiva dos primatas bípedes a que pertencemos, com a linguagem. Q uando isso ocorre, o viver na linguagem faz parte do fenótipo onto gênico que define nossa linhagem como linhagem cultural e em cuja conservação se dão todas as variações estruturais que levam ao ser biológico $\mathrm{H}$ omo sapiens sapiens. (Maturana, 1994, p. 142) 
Humberto Maturana e Francisco Varela, na década de 1970, revolucionam a Biologia e as Ciências Cognitivas com uma nova teoria sobre o funcionamento dos seres vivos na qual não separam os fenômenos da cognição do próprio processo de viver (Maturana \& Varela, 1991). Por esse motivo, chamam essa teoria de Biologia do Conhecer. Para dar conta dessa inseparabilidade como também da autonomia de um sistema vivo, eles elaboram o conceito de A utopoiesis. Essa expressão vem do grego, auto (por si mesmo) e poiesis (criação). Com ela, esses cientistas explicam a circularidade dos seres vivos em que produtor e produto se constituem mutuamente. Nos seres humanos, com a complexificação do sistema nervoso, aparece a linguagem e a consciência, que abrem possibilidades ilimitadas para a expansão do humano no sentido em que o processo evolutivo não é considerado em termos do princípio da "sobrevivência do mais apto" mas pelo da "deriva natural", que é produtor contínuo de diferenças. Assim sendo, por meio do mecanismo recorrente do "acoplamento estrutural" há sempre criação de soluções singulares em cada ato do ser vivo. É necessário dar ênfase aqui ao fato de que a Biologia da Cognição, inserida no rol das Ciências Cognitivas contemporâneas, não trabalha com especulações, como era a prática da Epistemologia até então, mas baseia-se em pesquisas empíricas em Neurofisiologia do maior rigor e reconhecidas pela comunidade científica internacional.

Uma longa história evolutiva mostra-nos o desenvolvimento do cérebro humano a partir dos primatas bípedes. Por meio de um contínuo "acoplamento estrutural", ou seja, uma recorrência entre organismo e meio, o cérebro foi se modificando em decorrência da plasticidade estrutural do organismo humano. 0 que se conserva neste fenômeno do viver não é a estrutura, mas a organização do vivo. É por isso que Maturana afirma em toda a sua obra que a aprendizagem é corporificada. O u seja, que o corpo participa dos "atos de linguagem". Para Flores \& Winnograd (1989), falar constitui-se em atos e não são meramente expressões de pensamento. Veremos mais adiante como isso aparece no fluir das conversações das pesquisadoras.

Uma "demanda autopoiética contínua" (idem) faz com que linguagem e cognição, por meio de ações efetivas, estejam sempre se constituindo socialmente em redes de conversações que configuram nosso mundo. Na perspectiva autopoiéitca não existe realidade 
pré-dada e, neste sentido, não haveria realidade ou conhecimento independente da ação do sujeito cognitivo. Esse pressuposto rompe com a tradição idealista, no sentido em que resgata a agência humana, como também com a empirista/ behaviorista, na medida em que 0 meio externo não determina 0 que acontece com 0 vivo, mas apenas perturba provocando uma mobilização produtiva interna. Trata-se, portanto, de uma dialógica que é chamada para dar conta de fenômenos complexos.

Por tudo isso, optamos pela metodologia da Dinâmica das Conversações para perseguir nossos objetivos neste estudo. Essa prática não segue nenhuma escola já consagrada, como a conhecida por Conversational A nalysis, por exemplo. Mas ela foi constituída por nós com base nos principais referenciais teóricos e a partir das necessidades específicas de investigação do nosso projeto de pesquisa. 0 que aconteceu na realidade é que fomos construindo "nosso caminho ao andar", como diria o poeta, com a necessidade de incluir o observador na pesquisa e a de entender seu processo de observar. 0 novo paradigma propõe-nos o desafio: se não separamos realidade interna de realidade externa, fica muito difícil sustentarmos um conhecimento objetivo e, por isso, precisamos explicitar para nós mesmas nossos processos de pensamento. É exatamente por esse motivo que apelamos para os princípios cibernéticos e trabalhamos com conceitos de segunda ordem como o pensar sobre o pensar, aprender como aprendemos e, principalmente, conhecer como conhecemos.

\section{Cibernética e A utopoiesis}

A revolução paradigmática que emergiu a partir do século XIX foi substituindo o cartesianismo por um sistema que se ia construindo em torno do conceito de auto-organização. A lógica formal inerente ao paradigma moderno já não dava mais conta dos fenômenos complexos que iam desafiando a ciência ao final do século XIX. Na primeira metade do século XX, com a Teoria dos Sistemas de Bertalanffy, fica cada vez mais clara a passagem de um paradigma com referência externa para um outro auto-organizativo. Essa idéia estava no centro das discussões das Conferências Macy em Nova York, onde um grupo de cientistas oriundos de diferentes campos do conhecimento se reuniu para pensar numa ciência unificada da 
mente. Nascia assim a Cibernética, cujos estudos foram fundamentais para o sucesso de um novo paradigma centrado no processo e não mais na substância.

Algum tempo mais tarde, já na segunda metade do século XX, os estudos de Ilyia Prigogine fazem uma releitura da II Lei da Termodinâmica, elaborada ainda no século XIX, segundo a qual tudo o que existe no universo tenderia para a morte térmica (entropia). Prigogine sugere que nos sistemas longe do equilíbrio, e os seres vivos são sistemas longe do equilíbrio bem como o são também a sociedade e a própria linguagem, essa tendência é revertida graças ao princípio da auto-organização. Assim, eles podem reverter a entropia por meio da interação, transformando-a em neguentropia. A lógica que subjaz a esses fenômenos sistêmicos e auto-organizativos não é mais uma lógica linear de causa/ efeito, mas uma lógica circular com retroações. Esses princípios estão no coração da Cibernética.

Heinz von Foerster, um dos mais brilhantes participantes das Conferências Macy, fundou a Biocibernética para estudar os fenômenos biológicos a partir dessa nova matriz cibernética. Ele concebe, então, o processo de vida como sistema fechado para informação e aberto para a energia, destacando o papel da interação e, naturalmente, o da auto-organização. Na esteira dos estudos de von Foerster, surgiu a teoria de Maturana \& Varela e o conceito de A utopoiesis.

O conceito de Autopoiesis é essencialmente um conceito cibernético na medida em que concebe 0 funcionamento do vivo como um circuito fechado de autoprodução, no qual o produtor e 0 produto se configuram circularmente. Nesse processo, conhecer e ser são processos inseparáveis. Como expressão dessa circularidade, Maturana \& Varela afirmam que: "Todo o fazer é conhecer e todo o conhecer é fazer" (1991, p. 13). É importante enfatizar aqui, para fins epistemológicos e ontológicos, que o paradigma cartesiano carrega uma fragmentação profunda, pois o sujeito que conhece está separado do objeto conhecido. Tudo se passa como se o sujeito cognitivo fosse independente de sua própria ação cognitiva.

A grande contribuição da Cibernética foi esse princípio integrador que coloca numa mesma paisagem seres vivos, natureza e máquinas. O conceito de Ecologia Cognitiva de Pierre Lévy (1994) serve como instrumental teórico importante para entender os pro- 
cessos cognitivos. Aí reside exatamente o rompimento com 0 cartesianismo, pois a característica fundamental desse paradigma se situa na fragmentação e na substancialização das coisas. A Cibernética trabalha com a integração de todas as dimensões da vida e da não-vida, bem como considera os processos e não as coisas. A mente, a aprendizagem e a vida são processos e não coisas. Por isso, seria mais adequado dizer que os seres vivos não "são", mas "acontecem" (Bennaton, 1984, p. 45).

A Biologia do Conhecer mostra-nos, ao observarmos o comportamento humano, uma inseparabilidade entre ser/ fazer/ conhecer/ falar a partir dessa visão sistêmica da Biocibernética. E é justamente por isso que temos diante de nós o problema do observador que não é mais alguém fora do sistema a observar uma realidade da qual não faz parte, mas um sujeito que tem que dar conta de sua própria ação ao operar. Trata-se do "observador implicado", como diz Maturana. Para ele, essa tarefa é fundamental para fazer ciência. Cito suas palavras:

(... ) um aspecto central do fazer ciência tem a ver com a nossa busca de compreender nossa experiência como seres humanos. E o sentido que dou a compreender é o da experiência de adotar uma operacionalidade de reflexão na linguagem, na qual podemos conhecer o que conhecemos nas circunstâncias de constituição na linguagem. (Maturana, 2001, p. 155)

Esse observador pensa sobre o seu pensar, sobre seu processo numa atitude metacognitiva que é potencializadora à de ser/ conhecer porque vai capacitando cada vez mais esse sujeito em termos de uma complexificação crescente. Ao fazer isso, estamos adotando as chamadas "metodologias de primeira pessoa" (Varela et al., 1991) numa tentativa de seguir a sugestão desses autores de incorporar as experiências pessoais à ciência, de forma profunda. Não estamos fazendo isso de forma arbitrária e sem rigor, mas contemplando a exigência científica de coleta de dados, interpretação, validação e busca de padrões, que organizam a experiência em torno da qualidade e não da quantidade. Trata-se aqui, portanto, da transição do sujeito mecânico do cartesianismo para o sujeito epistêmico, que se pensa a si mesmo no ato de viver/ observar.

Por todas essas razões expostas, fizemos a opção pela adoção da Dinâmica das Conversações como dispositivo metodológico fundamental. 


\section{As conversações em processo}

Nosso problema central de pesquisa, como já foi explicitado, é: Como se constitui o conhecimento num sistema fechado para informações e aberto para a energia (interações)?

O grupo faz uma busca teórica sistemática em publicações e traz esses dados para as reuniões de trabalho. Esse material bruto não constitui "informação" e muito menos conhecimento. A informação somente adquire sentido num processo de conhecimento que, por sua vez, é a própria ação do sujeito cognitivo/ ontológico. von Foerster esclarece-nos sobre isso; diz ele: "Informação nenhuma é exterior, ela só se encontra em nós mesmos" (Von Foerster, 1993, p. 203). E elas somente se constituem como tal na medida em que constituem um processo de conhecimento. Esse, por sua vez, é inseparável do processo de ser/ viver nas relações. O sujeito individual é uma abstração. Nós somente existimos na medida em que somos um nó numa rede de conexões. É, pois, no trabalho de discussão dos dados coletados que construímos o conhecimento em relação à questão. Uma nova etapa leva-nos a observar o que foi 0 nosso processo ao ouvir as fitas com as gravações das etapas anteriores.

A idéia aqui é que não existe realidade pré-dada, independente das ações dos sujeitos em interação. Por isso, vamos constituindo conhecimento e a nós mesmos nessa rede de conversações. Conhecimento, na perspectiva que estamos adotando, é ação efetiva e passa pelo processo de conversações.

Maturana lembra que "conversar" vem do latim cum (com) e versare (dar voltas) (Maturana, 1997). Então, o que o nosso grupo faz é dançar modulando emoções, palavras e corporalidade, entrando numa harmonia de muitas vozes. Com isso, podemos observar um pressuposto básico da teoria da A utopoiesis em ação: há um "acoplamento estrutural" constante, em que organismos (cada sujeito do grupo) e meio (o grupo) interagem de tal forma que ambos, grupo e sujeitos, mudam congruentemente. 0 que está fora (ambiente) não determina o que acontece individualmente com cada participante. A penas perturba e, essa perturbação mobiliza os seres para cada construção pessoal, para a autoria e singularidade. Como disse antes, trata-se de um fenômeno complexo, em que há conectividade e singularidade ao mesmo tempo. 
Essa "demanda de autopoiesis contínua" se dá não somente no nível celular, mas no nível da subjetividade e do conhecimento. Por isso, em cada situação que precisamos resolver apelamos para as conversações para responder a essa necessidade. Ao nos observar nas conversações, podemos ver então regularidades e recorrências que nada mais são que o próprio processo de "acoplamento estrutural" entendido como a modulação constante entre organismo e meio, constituindo a autopoiesis. Essas regularidades, portanto, não são individuais, mas constituem o domínio grupal que é sempre relacional e histórico.

Com base em todos esses pressupostos aqui tratados farei uma descrição de um momento de nosso processo de trabalho que envolve primeira e terceira pessoas em processo de conversações, para responder à questão central do projeto.

Ao discutir as leituras e elaborações teóricas envolvidas no marco teórico do trabalho, o grupo, ao ser observado pelas próprias observadoras (as reuniões são gravadas em fita cassete), percebe que há uma recriação da experiência e das próprias pesquisadoras. Cada vez que se discute a experiência, são geradas outras experiências e cada membro do grupo se expressa de maneira já transformada em cada recorrência das conversações. Como num processo autopoiético em qualquer nível, mudam as estruturas e conserva-se a organização (autopoiética). Nesse "acoplamento estrutural" há mudança estrutural no organismo porque há uma plasticidade estrutural do sistema nervoso e do organismo em geral. Cada vez que há um ato cognitivo, novas conexões acontecem no sistema nervoso.

A lógica subjacente a um grupo como esse é uma lógica nãolinear, pois o que um diz no grupo tem conseqüências em todos os outros de maneira singular e, ao mesmo tempo, as reações do grupo voltam ao autor da primeira mensagem numa atitude de retroação. Com isso, todos no grupo se reconfiguram e o grupo se reconfigura como um todo. Há mudança estrutural com novas conexões no cérebro e na sociedade. É verdade que nós, no limite investigativo de nosso trabalho, não podemos provar essas mudanças cerebrais e nem é esse nosso objetivo. Remetemos aos trabalhos de Antonio Damásio (2000) e Francisco Varela (artigos na web) para quem desejar ampliar este tema $O$ que podemos mostrar é a mudança cognitiva/ subjetiva de cada pesquisador no processo, bem como as conseqüên- 
cias sociais em termos de intervenções com docentes em oficinas autopoiéticas ou na transformação da própria performance didática de cada uma de nós. Vamos registrando as recursividades e transformações das diversas falas.

Para explicar a dinâmica das conversações do grupo usarei dois níveis de explicações que correspondem a duas fases do trabalho da pesquisa:

A- nível 1 - a discussão inicial da coleta de dados teórica e sua discussão com vistas à solução do problema.

B- nível 2 - um metanível que corresponde à audição das fitas e à análise dos comportamentos no grupo no processo de pesquisar.

Esse dois níveis são separados apenas para fins operacionais, pois basicamente 0 que acontece em qualquer nível de conversações é sempre a presença de alguns princípios cibernéticos. Refletirmos sobre o segundo nível é apenas uma questão de posição do observador que somos nós mesmos.

Vejamos, então, o que acontece no grupo de conversações tendo em vista a questão colocada a seus membros: Como se constitui 0 sujeito cognitivo numa rede como essa?

Há nesse processo uma circularidade na medida em que a causa inicial provoca efeitos que rebatem de volta sobre ela. Assim, o pesquisador " $\mathrm{X}$ " traz uma situação seja em forma de uma nova questão ou sobre uma elaboração que teria feito sobre o problema. Isso repercute nos demais de formas muito singulares (autopoiéticas). 0 pesquisador " $Y$ " responde ao pesquisador " $\mathrm{X}$ " de tal forma que cada vez que há uma resposta toda a rede se reconfigura. Isso pode ser evidenciado pela qualidade das respostas de cada pesquisadora, bem como nas novas formas em que vai tomando o grupo. Há sensíveis transformações. O próprio projeto inicial de pesquisa vai se reconfigurando. Então, um outro princípio que subjaz a isso tudo é o da topologia: a forma do grupo e dos participantes vai sendo dada pelos movimentos dos sujeitos cognitivos e não por uma organização prévia. Não mais se trata do objeto imóvel aristotélico, mas de um processo que não lida com propriedades ou substância, mas baseia-se em relações. Como diz Maturana: "A vida é poesia constante" considerando o sentido de poiesis como produ- 
ção. Há produção e autoprodução constantes dos seres vivos, dos humanos e da sociedade num continuum, da célula aos grupos sociais. Nessa produção, há sempre criação de novidades, de diferença. Por isso, não podemos, ao final da pesquisa, fazer generalizações.

Para avançar um pouco mais nessas explicações, lanço mão dos princípios cibernéticos que nos mostram a constituição da realidade/ conhecimento como resulta do efetivo desempenho de um sistema numa autonomia que tem na recursividade sua sustentação e autocorreções constantes. As falas das pesquisadoras apontam para recursividades que garantem as autocorreções constantes do grupo rumo a elaborações cada vez mais aproximadas do objeto de pesquisa. Von Foerster pode reforçar essa argumentação:

O ra, a cibernética é precisamente a ciência que concebe uma teoria da ação que pode dar conta de sua própria operacionalidade; ela fornece também um fundamento matemático, epistemológico e filosófico para as ações nas quais o operador-observador está incluído no sistema, onde ele opera sobre sua própria observação. (Von Foerster, op. cit., p. 200)

Num metanível, ou seja, naquele no qual ouvimos as discussões já feitas, e discutimos sobre as discussões, há uma metacognição constante porque estamos pensando sobre 0 nosso processo de pensar e de constituir conhecimento. Nesses momentos, não somos mais sujeitos mecânicos, mas sujeitos epistêmicos. Não um sujeito epistêmico universal piagetiano, mas um sujeito que se singulariza como subjetividade. Ao se fazer isso, aumenta de forma quântica 0 nível de consciência, melhorando nossa capacidade de controle sobre nossas próprias vidas e, assim, vamos abrindo para novos patamares de complexidade. Freqüentemente somos levados a crer que nos dispersamos e nos afastamos de nosso objeto de pesquisa, mas 0 pensar sobre isso nos reposiciona: o que ocorre é uma complexificação porque vamos levantando novos problemas sobre o problema central e sobre nós mesmas de uma maneira inseparável. Para Bergson (1991), conhecer é levantar problemas.

Alguém poderia argumentar que essas aberturas nos impediriam de testar nossas hipóteses e aplicar testes objetivos de validação destas. Acontece que, como nos explica Varela, a experiência da consciência é um processo emergente e não está relacionada com dados objetivos, mas sim com processos vividos (Varela et al., 1991). 
A consciência surge a partir de uma dinâmica não-linear. Por isso, ela emerge na experiência das redes de conversações.

\section{Considerações finais}

Na verdade, não pretendo trazer conclusões, mas, à maneira de Bergson, apenas inventar novos caminhos para tratar a experiência consciente na construção de conhecimento/ sujeito. Não se reflete sobre algo, mas a reflexão é a própria experiência. Por isso, ao refletirmos sobre nossa experiência nós estamos em plena ação e, portanto, transformando-nos com essa experiência/ nesta experiência. Somente uma metodologia capaz de dar conta da realidade em trânsito que incorpora a experiência pessoal numa perspectiva disciplinada poderá responder ao intricado problema com o qual nós nos desafiamos a nós mesmas.

Da mesma forma, mantendo uma coerência teórica entre os vários modelos conceituais apresentados com base na Cibernética, podemos dizer que não existe uma validação externa, mas as coerências de nosso operar no grupo é que vão nos autovalidar. Para encerrar, justifico essa afirmação com as próprias palavras de Von Foerster (1996, p. 130): "Não seria, por acaso, mais recomendável renunciar ao critério de Popper e buscar princípios fundamentais para uma teoria que se confirme na práxis?".

Recebido em junho de 2003 e aprovado em julho de 2003.

\section{Referências bibliográficas}

BENNATO N, J. 0 que é cibernética? São Paulo: Brasiliense, 1984.

BERGSON, H. L es deux sources de la morale et de la religion. 100. ed. Paris: PUF, 1961.

DAMÁSIO, A. 0 mistério da consciência. São Paulo: Companhia das Letras, 2000.

FLO RES, F.; WINNOGRAD, T. H acia la compresión de la informática y la cognición. Barcelona: Hispano-Europea, 1989.

LÉVY, P. Tecnologias da inteligência. São Paulo: Editora 34, 1994. 
MATURANA, H. El sentido de lo humano. Santiago: Dolmen, 1994.

MATURANA, $\mathrm{H}$. L a realidade: objetiva o construida? Barcelona: Anthropos, 1997. v.1.

MATURANA, H. Transformación. Santiago: D olmen, 1999.

MATURANA, H. Cognição, ciência e vida cotidiana. Belo Horizonte: UFMG, 2001.

MATURANA, H.; VARELA, F. El árbol del conocimiento. Santiago: Hachette, 1991.

VARE LA, F. El fenomeno de la vida. Santiago: D olmen, 1999.

VARELA, F. Francisco Varela's home page: articles on neurophenomenology and first person methods. Disponível em <http:/ / web.ccr.jussieu.fr/ varela/ human_ consciousness/ article01.html> Acesso em 2003.

VARELA, F.; THOMPSON, E.; ROSH, E. The embodied mind: cognitive science and human experience. Cambrigde, Mass.: MIT, 1991.

VON FOERSTER, H. Entrevista a G uitta Pessis-Pasternak. In: Pessis-Pasternak, G. D o caos à inteligência artificial. São Paulo: Unesp, 1993.

VON FOERSTER, H. Reflexiones ciberneticas. In: FISCHER, H.R. et al. El final de los grandes proyectos. Barcelona: G edisa, 1996. 